\title{
REVISTAMARACANAN
}

Dossiê

\section{Fraturas contemporâneas de histórias indígenas em Belém: sobre mármores e grafites}

\section{Contemporary fractures of indigenous stories in Belém: on marbles and}

\author{
grafitess
}

\author{
Ivânia dos Santos Neves* \\ Universidade Federal do Pará \\ Belém, Pará, Brasil
}

Recebido em: 31 dez. 2019.

Aprovado em: 06 maio 2020.

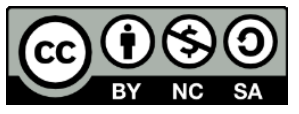

\begin{abstract}
As pesquisas que deram ensejo a este artigo foram desenvolvidas no âmbito do projeto " 400 anos depois: experiências nas paisagens de Belém", financiado com recursos do Conselho Nacional de Desenvolvimento Científico e Tecnológico - CNPq, Brasil.

* Professora Titular do Instituto de Letras e Comunicação da Universidade Federal do Pará, atuando na graduação e no Programa de Pós-graduação em Letras. Doutora em Linguística, na área de Análise do Discurso, pela Universidade de Campinas; Mestre em Antropologia e Licenciatura em Letras pela Universidade Federal do Pará. (ivanian@uol.com.br)
\end{abstract}

ORCID iD: https://orcid.org/0000-0002-6738-5254

CV Lattes: http://lattes.cnpq.br/2648132192179863 


\title{
Resumo
}

Neste artigo, considerando como referência teórico-metodológicas os estudos do discurso fundamentados em Michel Foucault e as definições de dispositivo colonial e etniCidades para compreender os enunciados visuais espraiados nas paisagens de Belém na segunda década do século XXI, que representam diferentes lugares de enunciação sobre a história da cidade e os povos indígenas. Tomo o frontal da Basílica de Nazaré e uma escultura de bronze de um indígena exposta na praça de um bairro nobre da cidade para marcar o discurso da colonização e, em contrapartida, analiso grafites de dois artistas contemporâneos paraenses que retomam a memória indígena de Belém em suas produções e visibilizam a pluralidade étnica da cidade. De certa forma, atualizo a antiga metáfora cunhada pelo Pe. Antônio Vieira, mas agora, em oposição ao mármore, não mais a murta e sim os grafites e sua efemeridade.

Palavras-chave: Dispositivo Colonial. Cidades. Diversidade. Colonialidade.

\begin{abstract}
In this article, considering as a theoretical-methodological reference the discourse studies based on Michel Foucault and the definitions of colonial dispositive and ethniCity to understand the visual statements spread in the landscapes of Belém in the second decade of the 21st century, representing different places of enunciation about the history of the city and the indigenous peoples. I analyze the frontal of the most famous catholic church of the city and a bronze sculpture to mark the discourse of the colonization and, in contrast, I analyze graffiti of two local contemporary artists that retake the indigenous memory of Belém in their productions. In a way, update the ancient metaphor coined by Fr. Antonio Vieira, but now, as opposed to marble, not the myrtle but graffiti and its transience.
\end{abstract}

Keywords: Colonial Dispositive. Cities. Diversity. Coloniality. 
A estátua de mármore custa muito a fazer, pela dureza e resistência da matéria; mas, depois de feita uma vez, não é necessário que Ihe ponham mais a mão: sempre conserva e sustenta a mesma figura; a estátua de murta é mais fácil de formar, pela facilidade com que se dobram os ramos, mas é necessário andar sempre reformando e trabalhando nela...

Pe. Antônio Vieira

\section{Introdução}

A cidade de Belém, capital do estado do Pará e segunda maior cidade da Amazônia brasileira, no ano de 2016 completou 400 anos e este aniversário, assim como acontece com as cidades latino-americanas, toma como referência o início da colonização na região. Esse período festivo remexeu a memória dos moradores da cidade, fomentando diversas manifestações, tanto de movimentos políticos reivindicatórios, quanto de cunho artísticoculturais favoráveis ou não à comemoração. Este acontecimento fez insurgir com mais visibilidade os processos discursivos que forjaram uma espécie de história oficial da cidade, vinculado apenas à presença europeia.

Alinhada ao projeto de expansão da colonização ibérica na América Latina, Belém foi constituída a partir de uma pluralidade étnica, que começou com o genocídio de muitas sociedades indígenas e a vinda forçada de milhares de africanos escravizados. A história deste território que denominamos de Amazônia brasileira, cuja conquista se inicia com a fundação da cidade de São Luís no Maranhão, no início do século XVII, foi escrita pelo colonizador, mas gradativamente, a partir das reivindicações dos movimentos indígenas, começa a exibir suas fraturas e outros enunciadores ganham visibilidade nesta dinâmica de contar a história da região.

A produção de verdades a partir das mais diferentes mídias analógicas e digitais instituídas pela colonização e suas potentes estratégias de institucionalização na memória e no corpo dos povos subalternizados representam o que defino, a partir de Michel Foucault e dos estudos decoloniais, como "dispositivo colonial". Observo através das linhas deste dispositivo como ele estabelece os enunciadores autorizados da história e como ele é obrigado a se reposicionar, diante da insatisfação com uma história única. ${ }^{1}$

Este processo contínuo e difuso envolve poderes globais e estratégias de colonização interna, no entanto, ele foi sempre marcado pela resistência e entre outros efeitos, produziu

\footnotetext{
${ }^{1}$ NEVES, Ivânia. A Invenção do índio e as narrativas orais tupí. 2009. Tese (Doutorado em Comunicação) - Universidade de Campinas, Campinas (SP), p. 27.
} 
nas sujeitas e nos sujeitos das sociedades latino-americanas uma condição de "estar ou sentirse entre". ${ }^{2}$ A história nunca se reduziu às versões contadas pelos primeiros colonizadores da América e por seus herdeiros, afinal, ela se pluralizou.

A diferença colonial cria condições para situações dialógicas, nas quais se encena, do ponto de vista subalterno uma enunciação fraturada como reação ao discurso e à perspectiva hegemônica. Assim, o pensamento liminar é mais do que uma enunciação híbrida. É uma enunciação fraturada em situações dialógicas com a cosmologia territorial e hegemônica. ${ }^{3}$

Neste artigo, analiso enunciados visuais espraiados nas paisagens de Belém na segunda década do século XXI, que representam diferentes lugares de enunciação. Aqui, mostro como apesar dos intensos processos de apagamento, as matrizes culturais indígenas estão presentes na constituição da cidade. Para isso, primeiro analiso o frontão da Basílica de Nossa Senhora de Nazaré e a escultura de um indígena exposta no centro da Praça Brasil, localizada num dos bairros nobres da cidade. Estes dois enunciados são recorrentes em análises da história da cidade, mas a análise não se limita a estes monumentos institucionalizados pela igreja católica e pela prefeitura.

Independentes e muitas vezes na contramão das instituições existem as sujeitas e os sujeitos ordinários que se apropriam das cidades e Ihes dão significados insubmissos. ${ }^{4}$ Então, para além dos "lugares do patrimônio", também analiso um movimento bastante expressivo em Belém na última década, o grafite de rua e seu potencial de resistência, que retoma as memórias indígena e africana da cidade. Mais especificamente, procuro mostrar como o grafite visibiliza a presença indígena silenciada no patrimônio oficial.

De certa forma, atualizo a antiga metáfora cunhada pelo Pe. Antônio Vieira, mas agora, em oposição ao mármore, não mais a murta e sim os grafites e sua efemeridade. Em suas diferentes linguagens, estes enunciados são aqui analisados como monumentos, que precisam ser compreendidos em suas dimensões arqueológicas, para que se iluminem as redes de memórias e os jogos de poder em que estão envolvidos e não considerados como documentos inertes, fantasiosamente neutros e protegidos por uma verdade incontestável, como propõe Michel Foucault. ${ }^{5}$

Proponho também uma reflexão sobre a noção com que procurei problematizar a pluralidade étnica das cidades latino-americanas e seus diferentes processos discursivos: etniCidade. Minhas análises, aqui, tomaram como objeto as relações de poder que envolvem a presença indígena na história oficial e não oficial da cidade de Belém, neste início de século.

A letra " $C$ " escrita em maiúsculo é uma construção proposital, para marcar uma diferença conceitual, porque a etniCidade a que me refiro não está ligada àquela definição da

\footnotetext{
2 MIGNOLO, Walter. Histórias Locais / Projetos Globais: Colonialidade, Saberes Subalternos e Pensamento Liminar. Belo Horizonte: Ed. UFMG, 2003, p. 11.

${ }^{3}$ Ibidem, p. 11.

${ }^{4}$ DE CERTEAU, Michel. A invenção do cotidiano. Vol. 1: Artes de fazer. Petrópolis, RJ: Vozes, 1998, p. 37.

${ }^{5}$ FOUCAULT, Michel. Sobre a História da Sexualidade. In: Microfísica do poder. Rio de Janeiro: Graal, 2007, p. 122.
} 
antropologia, agora ultrapassada, imbricada com um discurso de raças puras. EtniCidade, aqui, está relacionada a uma compreensão da pluralidade cultural das cidades, da diversidade na composição étnica das cidades. Necessariamente, nesta perspectiva, o discurso sobre a homogeneidade das cidades é refutado, afinal, chega a ser ingênuo acreditar em uma única concepção de cidade.

Quando me refiro mais especificamente a etniCidades amazônicas, assinalo um grupo de singularidades associadas a diferentes processos históricos e culturais marcados pela presença do colonizador europeu, a princípio, mas depois agenciados por poderes locais bastante imbricados com o capital estrangeiro. Também entendo as sociedades amazônicas, em todas as suas diversidades, constituídas por sujeitos historicamente construídos cujos lugares de enunciação ainda são bastante nebulosos. Para Ana Pizarro:

A Amazônia é uma região cujo traço mais geral é o de ter sido construída por um pensamento externo a ela. Ela tem sido pensada em nível internacional, através de imagens transmitidas pelo ideário ocidental, europeu, sobre o que eles entendem ser sua natureza, ou em outras palavras, sobre o lugar que a Amazônia ocupou na sua experiência. ${ }^{6}$

A outra noção, o dispositivo colonial, fundamentada no conceito de dispositivo proposto por Michel Foucault e nas discussões latino-americanas de decolonialidade do poder, procura mostrar a partir de diferentes enunciados espraiados pela cidade de Belém como as práticas discursivas impostas pelo sistema colonial e as relações de subalternização ainda estão intensamente presentes no cotidiano da cidade e nos discursos que circulam sobre ela.

\begin{abstract}
Este grande dispositivo, o sistema colonial, engloba o poder colonial das metrópoles europeias e a colonialidade, que representa sua atualização, com seus diferentes matizes, prossegue nas histórias das sociedades amazônicas e em muitas outras histórias da América Latina, a moeda colonialidade/modernidade continua a se atualizar e ela está intensamente presente, sobretudo nas ações do poder público na cidade. ${ }^{7}$
\end{abstract}

O dispositivo colonial, com suas potentes estratégias de poder, se atualiza e se reconfigura através das novas elites que surgiram após a independência do Brasil no século XIX, um processo semelhante ao que aconteceu em outros países da América Latina. Como lado mais frágil, do ponto de vista político, no Estado brasileiro, a Amazônia experimenta, desde a independência política de Portugal, uma condição de colônia diante das decisões tomadas no Centro-Sul do Brasil.

O dispositivo colonial instituiu universidades e institutos de pesquisa eurocentrados, espalhados por todo este continente e tratou de eleger a narrativa colonial como a história verdadeira, assim também como estabelecer seus enunciadores autorizados. Permeável pelas condições de possibilidades históricas, este dispositivo pode oscilar e estrategicamente visibilizar as matrizes culturais subalternas, mas não declina do poder de autorizar ou desautorizar o que deve ser considerado como história. Assim, acompanhamos a criação de

\footnotetext{
${ }^{6}$ PIZARRO, Ana. As Vozes do Rio. Belo Horizonte: Ed. UFMG, 2012, p. 31.

7 NEVES, Ivânia. EtniCidades: os 400 anos de Belém e a presença indígena. Revista Moara, $\mathrm{n}$. 43, jan.-jul. 2015, p. 31.
} 
agências estatais em toda a América Latina ligadas de alguma forma a um poder internacional da ONU (Organização das Nações Unidas), responsáveis por definir patrimônio nacional e patrimônio da humanidade. No Brasil, uma das mais exitosas expressões é o IPHAN (Instituto do Patrimônio Histórico e Artístico Nacional), que nas últimas gestões, depois da última ditadura militar, passou a se empenhar no sentido de incluir a diversidade cultural do Brasil.

As fundações das primeiras cidades latino-americanas envolveram duros processos belicosos, produziram genocídios indígenas, mas também introduziram novas práticas religiosas, novas línguas, novas cosmologias. O que somos hoje parte desta pluralidade de interesses e não aconteceu uma pacificação absoluta de nossa pluralidade étnica. Em relação às cidades, sugere Lucrécia Ferrara:

\begin{abstract}
Embora persuasiva e publicitária, a função-valor da paisagem não é capaz de desvencilhá-la da atração imaginária que a transforma em poder mediativo. É essa força que permite, à cidade, ultrapassar a simplicidade da troca imposta pelo mercado da imagem urbana e alcançar expressivo capital simbólico que impõe uma dialética entre a cidade e sua paisagem, entre a sedução publicitária e a imagem, entre a razão que constrói a imagem e a imaginação que permite a autonomia de produzir outras identificações. Nesse sentido, a paisagem da cidade é, sobretudo, de natureza comunicativa e interativa porque, se não se faz sem registros, também não dispensa vínculos afetivos. ${ }^{8}$
\end{abstract}

Nas análises a seguir, tomarei a escultura, a pintura, os grafites e a própria cidade como enunciados, materialidades produtoras de sentidos. A partir desta perspectiva coloco meus olhos nas paisagens de Belém, para entender a insistente presença indígena na constituição do patrimônio cultural da cidade.

\title{
Entrando nas etniCidades amazônicas e suas contradições
}

Desde 1998, desenvolvo projetos de pesquisa e extensão com sociedades indígenas de língua e tradição tupi. Grande parte destes trabalhos se dividiu em pesquisas de campo nas terras indígenas e na análise da presença indígena em diferentes mídias. Somente a partir de 2014, comecei a me interessar pela presença indígena na formação das cidades na Amazônia. $\mathrm{Na}$ verdade, estudar as cidades representou, naquele momento, o desejo de trabalhar com outras sujeitas e outros sujeitos não indígenas, supostamente constituídos por outras emergências históricas. Decidi, então, começar os estudos sobre discursos e cidades em Belém, a cidade onde moro.

Este caminho, no entanto, muito antes de me distanciar dos povos indígenas, acabou por me mostrar novas perspectivas da colonização e de como as cidades se impuseram como uma das mais efetivas estratégias do dispositivo colonial. Continuei, portanto, trabalhando com a história dos povos indígenas na Amazônia, porque, considerando a perspectiva teóricometodológica com que analiso as movências históricas, não há como pensar Belém sem pensar

${ }^{8}$ FERRARA, Lucrécia. As mediações da paisagem. Revista Líbero, São Paulo, v. 15, n. 29, p. 43-50, 2012, p. 48. 
a participação indígena. Assim também, como é muito difícil, pensar qualquer cidade da Amazônia, quiçá da América Latina, sem pensar essa composição étnica tão plural das cidades silenciadas pela colonização europeia. Hoje, diria mesmo que qualquer cidade guarda em si sua pluralidade étnica, constituída por emergências históricas singulares.

A fundação das cidades paraenses aconteceu, em linhas gerais, a partir de dois diferentes momentos históricos. Os primeiros municípios, como Belém, Vigia, Cametá e Bragança, ainda no período colonial, a partir do século XVII, nasceram às margens dos rios da bacia amazônica e tinham como principal objetivo garantir a posse portuguesa desta região, bastante ameaçada pela presença francesa. Mais recentemente, já no século XX, no rastro da construção de grandes rodovias voltadas à integração nacional da Amazônia, e dos grandes projetos de exploração mineral, de agropecuária e de hidroeletricidade, para citar apenas os mais expressivos, pequenas cidades surgiram no interior do estado, como é o caso de Paragominas, Ulianópolis, Goianésia.

Durante os longos séculos de colonização, neste continente, a construção das cidades representou uma das mais poderosas estratégias disciplinadoras das práticas culturais dos indígenas e dos povos africanos. Elas representaram o mais preciso ponto de inserção na realidade desta configuração cultural e se consolidaram como um modelo urbano de duração secular, ainda muito presentes na América Latina: a "cidade barroca". 9 A palavra europeia prescindia de novos espaços para a encenação de seus rituais. A arquitetura colonial com suas igrejas e suas escolas, muitas vezes construídas por sobre lugares indígenas sagrados, representa, hoje, em cidades como Olinda, em Pernambuco e Ouro Preto, em Minas Gerais patrimônio cultural da humanidade.

Na Amazônia, outra estratégia que contribuiu para o apagamento da pluralidade étnica foi a construção discursiva da cidade ribeirinha. Embora este enunciado tenha se estabelecido como uma espécie de verdade "oficial" sobre as cidades da região é necessário problematizálo. Usar a classificação de ribeirinha é uma significativa forma de apagar a memória indígena e a memória africana dessas cidades. Para ilustrar este processo, podemos imaginar uma versão bastante tendenciosa da história, em que os ribeirinhos estavam nas beiras dos rios da Amazônia no momento da chegada dos europeus. Nesta produção de verdades, não eram os indígenas, mas sim os ribeirinhos, cuja vinculação étnica é pejorativa e desvinculada de cosmologias próprias, uma espécie de não-lugar.

Não se devem analisar os sentidos de ribeirinho fora de uma perspectiva política. A palavra ribeirinha, neste sentido, nasceu na Universidade Federal do Pará, no final dos anos de 1980, para substituir a palavra caboclo, como uma forma de minorar o preconceito com a população local da Amazônia. ${ }^{10}$ Nos textos literários produzidos na região, antes desse período, ou mesmo na literatura científica não aparece o enunciado ribeirinha.

${ }^{9}$ Cf.: RAMA, Angel. A cidade das letras. São Paulo: Brasiliense, 1985.

10 DAMASCENO, José. Entre o rio e a ponte: letras e identidades às margens do Rio Acará, na Amazônia paraense. 2012. Dissertação (Mestrado em Comunicação, Linguagem e Cultura) Universidade da Amazônia, Belém, p. 52. 
De qualquer forma, hoje, não há como pensar em cidades amazônicas e não considerar a classificação de ribeirinhas, mas não podemos ignorar que se trata de uma estratégia discursiva de apagamento da etniCidade. Por outro lado, é também preciso esclarecer que não desejo esquadrinhar identidades fixas e nem acredito ser possível encontrar o indígena ou o negro dentro de uma pureza universal e inicial. Ao contrário disso, desejo visibilizar a pluralidade étnica e dependendo das práticas discursivas em que está envolvida, a classificação de cidade ribeirinha encurta essa possibilidade.

No Brasil contemporâneo, notadamente depois da promulgação da Constituição de 1988, o respeito às liberdades individuais, a organização dos movimentos sociais e a abertura das universidades públicas às cotas étnico-raciais favoreceram a visibilidade das condições sociais em que vivem os mais de trezentos povos indígenas no Brasil, num cenário bastante heterogêneo, com um número bastante expressivo de indígenas vivendo nas cidades. Segundo o IBGE mais de trezentos mil indígenas vivem nas cidades brasileiras. ${ }^{11}$

A cidade e o seu patrimônio trazem à tona essas questões de interesse para as
teorias sociológica e antropológica. A heterogeneidade da sociedade complexa
moderno-contemporânea, manifestada dramaticamente nas grandes cidades e
nas áreas metropolitanas, aponta para as dificuldades e as limitações de uma
ação pública responsável pela defesa e pela proteção de um patrimônio cuja
escolha e definição implica necessariamente arbítrio e, em algum nível, exercício
do poder. Voltamos à velha questão de saber se sempre há vencedores e
perdedores, ou seja, em cada caso e situação é preciso estar atento para
procurar avaliar os custos e os ganhos das decisões que são tomadas e dos
valores que as sustentam. ${ }^{12}$

A presença dos negros e depois dos povos indígenas nas universidades começou a desalojar alguns redutos de poder instituídos no Estado brasileiro. Ainda que num processo muito inicial, os próprios indígenas que chegaram à conclusão de cursos superiores e mesmo na pós-graduação, começam a se autorizar como enunciadores de sua própria história e a contestar o lugar dos pesquisadores. Não se trata, no entanto, de um processo pacífico, ao contrário, há uma grande resistência de setores mais conservadores da sociedade brasileira e o corte das verbas destinadas aos indígenas e remanescentes de quilombolas é uma ameaça real a estas conquistas.

A universidade brasileira, nos últimos dez anos, ainda que seja apenas pela presença nas salas de aula e não nos currículos historicamente monoculturais e eurocêntricos, também passou a se pluralizar com a presença de novas sujeitas e sujeitos em seus espaços. Essa condição histórica de exclusão destas populações nas universidades, instituição que autoriza os saberes na sociedade brasileira, é um braço forte do colonialismo. Como pensar a diversidade étnica de uma cidade, se apenas uma cosmologia, a eurocêntrica, se estabelece como um saber a ser respeitado?

${ }^{11}$ PEREIRA, Nilza. Uma visão espacial e sociodemográfica da população indígena no Brasil, com base no Censo Demográfico 2010. In: INSTITUTO Brasileira de Geografia e Estatística. Atlas Nacional Digital do Brasil 2016. (Recurso Eletrônico). Disponível em: https://www.ibge.gov.br/apps/atlas_nacional/. Acessado em: 15 dez. 2019.

${ }_{12}$ VELHO, Gilberto. Patrimônio, negociação e conflito. Mana, Rio de Janeiro, PPGAS/MN/UFRJ, v. 12 , n. 1 , p. 237-248, 2006, p. 246. 


\title{
O dispositivo colonial e os 400 anos de Belém
}

Assim como São Luís em 2012 e outras cidades do litoral norte do Brasil, em 2016, Belém fez quatrocentos anos e todas as tensões que envolveram as comemorações desta data estão imbricadas com o dispositivo colonial. No continente americano, estes aniversários retomam a colonização como um marco positivo de civilidade e progresso, como se não houvesse sociedades que já escreviam suas histórias antes da chegada dos europeus.

A fundação das cidades no litoral norte, no início do século XVII marcou o início da segunda colônia portuguesa na América do Sul, a Província do Grão-Pará e Maranhão, cuja história é bem pouco visibilizada na história do Brasil. Para a maioria dos brasileiros, quando D. Pedro I proclamou a independência, o Brasil se constituía neste imenso território da atualidade. A província do Grão-Pará e Maranhão resistiu bastante a ser incorporada ao Império brasileiro. Não foi de imediato, nem de forma pacífica que esta região se transformou no que hoje conhecemos como Amazônia brasileira.

A história colonial começou a ser registrada desde a chegada das primeiras embarcações, nas cartas dos cronistas que eram endereçadas aos reis de Portugal e de Castela e pelos textos produzidos pelos primeiros religiosos que junto com eles chegaram. Na América inteira, do século XV ao século XIX também houve uma série de pesquisas de naturalistas, que documentaram com livros e imagens as relações sociais entre os índios, africanos, a população regional e os processos de formação social das cidades amazônicas. Nestes processos, estas sociedades passaram a ser bastante estereotipadas. Para Maués:

\begin{abstract}
Há diversos estereótipos em voga sobre a Amazônia, região periférica em relação ao Brasil e ao mundo. Uma dessas versões estereotipadas tem características mais ou menos eruditas. Nela, a Amazônia é pensada, basicamente, no que diz respeito a seus aspectos humanos e sociais, como área essencialmente indígena e habitada, também, por populações neobrasileiras hostis a esses índios, assim como por ocupantes motivados por interesses alienígenas, muitos deles vinculados a "grandes projetos", perniciosos à natureza e ameaçadores do equilíbrio ecológico na grande região, mas cujos efeitos poderão se espalhar pelo mundo todo, com consequências calamitosas para a humanidade. ${ }^{13}$
\end{abstract}

Esse traço de ser construída discursivamente pelo pensamento externo continua produzindo, mesmo entre os moradores da região, um sentimento forjado de se sentir no lugar do colonizador, um processo reforçado pelo desconhecimento de sua própria história. Até a denominação da região está envolvida nestes jogos de poder, pois a palavra Amazônia, assim como a famosa Lenda das Amazonas, não está relacionada diretamente à cosmologia de nenhuma das sociedades indígenas. Amazon é um radical grego, assim como a narrativa envolvendo mulheres guerreiras também faz parte da cosmologia da Grécia Antiga. Esta

13 MAUÉS, R. H. Outra Amazônia: os santos e o catolicismo popular. Norte Ciência, v. 2, n. 1, p. 1-26, 2011, p. 01. 
narrativa foi transposta para a América do Sul por portugueses e espanhóis, que inventaram um mito de nascimento da região amazônica. Nunca existiu uma sociedade indígena de mulheres guerreiras na região, trata-se de uma narrativa grega adaptada.

O nome Amazônia não traduz as cosmologias indígenas, embora o discurso construído pelos europeus seja tomado como uma verdade e todos acreditem nesta espécie de edição local da narrativa, em que mulheres indígenas valentes retiraram um dos seios para manusearem melhor suas armas. A própria autodenominação da região é uma construção do dispositivo colonial e o enunciado Amazônia faz parte do processo de apagamento dos saberes locais.

A história da América latina é a de um longo e demorado processo de incomunicação. Incomunicação, primeiro, entre os diferentes passados, o que teria permitido decifrar a conquista e a colônia como processo histórico e não como fatalidade de um destino. Aprisionados em uma história em que somente houve próceres e soldados, mas não povo, os dominados se verão incapazes de reconhecerem-se a si mesmos no processo histórico que fez deles primeiro escravos e depois dependentes. ${ }^{14}$

O dispositivo colonial sempre esteve imbricado com as mais diferentes mídias (das cartas dos viajantes às redes sociais de nossos dias), com os sistemas judiciários (nunca houve condenação ou mesmo retratação em relação às mortes dos indígenas) ${ }^{15}$, com o dispositivo escolar (a história ensinada em nossas salas de aula), em nossas conversas cotidianas, quando ouvimos que não existem mais índios de verdade e tantos outros enunciados pejorativos e hierarquizantes que se naturalizaram sobre os povos indígenas. Sem dúvida, a colonização elege um enunciador autorizado e a história oficial, até aqui se incumbiu de também atualizar quem pode e quem não pode falar sobre a região.

As experiências bastante heterogêneas de sujeitas e sujeitos que vivem na Amazônia podem ser bem diferentes do discurso externo que fala sobre a região sem a experiência local. Mas ninguém está fora das teias do discurso e mesmo as populações subalternizadas pelo dispositivo colonial podem tomar a negação da pluralidade étnica como uma verdade inquestionável e forjar também suas memórias, negando a descendência indígena ou africana.

Os acontecimentos narrados a seguir mostram como as práticas discursivas coloniais estão presentes no cotidiano dos morados da cidade de Belém. A próxima imagem, um grafite de Cely Feliz, desenhado em um muro na periferia de Belém e disponível no site da artista,

${ }_{14}^{14}$ MARTÍN-BARBERO, J. A Comunicação na Educação. São Paulo: Contexto, 2014, p. 27.

15 No dia 5 de fevereiro de 2018, a Corte Interamericana de Direitos Humanos condenou o Estado brasileiro por violação de direitos do povo Xukuru, que vive em Pernambuco. Mesmo não sendo uma condenação do sistema judiciário brasileiro, a sentença é significativa e pode representar uma jurisprudência sobre a reparação dos atos de violência praticados pelo Estado brasileiro aos povos indígenas. Para saber mais: OLIVEIRA, Regiane. Os indígenas que derrotaram o Governo brasileiro na Corte Interamericana. El País. (Site). Publicado em: 14 mar. 2018.2 Disponível em: https://brasil.elpais.com/brasil/2018/03/13/politica/1520949894_800892.html. Acesso em: 10 dez. 2019; CORTE Interamericana de Derechos Humanos. Caso Pueblo Indígena Xucuru y sus miembros vs. Brasil. Resumen de la Sentencia, 5 febrero de 2018. Disponível em: http://www.corteidh.or.cr/docs/casos/articulos/resumen_346_esp.pdf. Acesso em: 10 dez. 2019. 
analisado na dissertação de Camille Nascimento, produziu um ruído bastante significativo em relação ao silenciamento da constituição indígena dos moradores de Belém. ${ }^{16}$

Figura 01- "Pq nem todo risco no muro é masculino!"

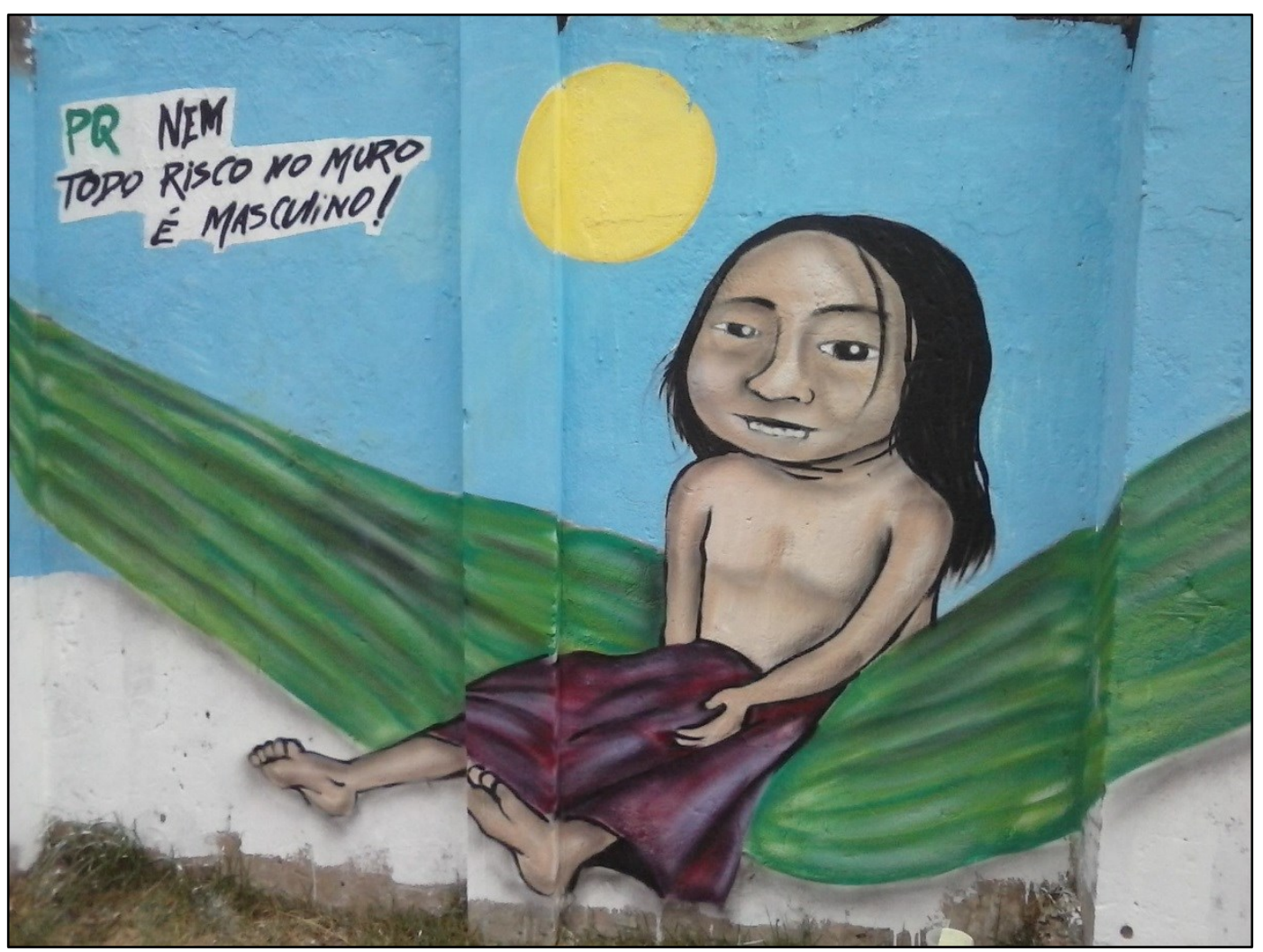

Fonte: [Reprodução]. [s./d.]. Disponível em: http://celyfeliz.yolasite.com/say-hello.php. Acesso em: 28 abr. 2015.

A exibição desta imagem durante eventos acadêmicos em diferentes regiões do Brasil dividiu a opinião do público a respeito do corpo indígena desta mulher. Nas ocasiões em que o trabalho foi apresentado em Belém, quando se atribuía a identidade indígena a esta mulher, recorrentemente, as pessoas refutavam e diziam: "Não, ela não é uma mulher indígena. Isto é uma mulher daqui de Belém, ali na esquina você vai encontrar alguém assim!". Havia uma resistência em aceitá-la como indígena, por sua semelhança com as mulheres de Belém.

Em outros estados, o trabalho foi apresentado e não houve qualquer discussão sobre a identidade desta mulher grafitada. Fora da Amazônia, ainda que existam povos indígenas em todas as regiões brasileiras, esta imagem é de uma mulher indígena. Diferente do que acontece na Amazônia, a identidade indígena não se impõe como condição a estes sujeitos, mesmo que tenham um fenótipo indígena. Para grande parte dos sujeitos não indígenas da região amazônica, esta memória está associada a não ser civilizado e o discurso de que

16 NASCIMENTO, Camille. A presença indígena nos grafites de Belém: entre fraturas e resistências. 2017. Dissertação (Mestrado em Comunicação) - Universidade Federal do Pará, Belém, p. 21-22. 
"Amazônia é terra de índio" precisa ser refutado. Vemos nestas situações como o dispositivo colonial se estabelece no corpo e em suas possíveis leituras. Como assevera Michel Foucault:

O dispositivo, portanto, está sempre inscrito em um jogo de poder, estando sempre, no entanto, ligado a uma ou a configurações de saber que dele nascem, mas que igualmente o condicionam. É isto, o dispositivo: estratégias de relações de força sustentando tipos de saber e sendo sustentadas por eles. ${ }^{17}$

Por outro lado, assim como o dispositivo colonial atualiza as suas formas de dominação e exploração nas cidades amazônicas, a resistência a este processo também se atualiza em novas formas de respostas a essas investidas indiscriminadas. E da mesma forma como existe uma investidura em apagar a memória indígena das cidades, as sujeitas e os sujeitos que fazem a história do presente nas cidades resistem.

\section{Onde estão os indígenas nas paisagens de Belém?}

Nesta segunda parte, analiso as condições em que os indígenas aparecem no patrimônio cultural da cidade de Belém. É necessário, no entanto, lembrar de que não existem sociedades indígenas organizadas vivendo em terras indígenas na área metropolitana da cidade. Por outro lado, aceitar que os povos indígenas nativos desta região foram totalmente exterminados durante o início da colonização é reforçar o dispositivo colonial.

Houve sim grandes genocídios indígenas para a imposição das cidades e além das mortes, é certo que uma boa parte dos indígenas se valeu da estratégia de fugir para o interior da floresta e se resguardar das fronteiras da colonização. Ainda hoje, imagens de satélite atestam a existência de mais de 60 grupos de índios isolados na floresta amazônica. Há de se considerar, porém, que grande parte destas sociedades foi incorporada à população pobre da cidade e foram elas, junto com africanos escravizados, a mão-de-obra que construiu o patrimônio arquitetônico colonial de Belém. Também podemos ver nos trágicos índices das chacinas nos bairros periféricos da cidade como os corpos mortos exibem em seus fenótipos a memória indígena e africana da cidade.

$\mathrm{Na}$ reação do público diante do grafite da mulher indígena pintada por Cely Feliz, podemos observar como esta memória está presente no corpo dos moradores da região. Para os olhos de um estrangeiro que chegue à cidade, o fenótipo de grande parte da população revela uma Belém indígena e o mergulho nas práticas culturais reforça ainda mais este discurso. A culinária paraense, tão cara à população da cidade e hoje conhecida no mundo todo, não esconde a tradição indígena.

Assim como a cidade está dividida em bairros nobres e periféricos, o patrimônio cultural, que supostamente atenderia apenas a critérios estéticos, também obedece a esta

\footnotetext{
${ }^{17}$ FOUCAULT, Michel. Em defesa da sociedade: curso no College de France (1975-1976). São
} Paulo: Martins Fontes, 2005, p. 146. 
partilha de poder. Durante séculos, no Brasil, o dispositivo colonial estabeleceu como alta cultura os padrões europeus e marginalizou as tradições indígenas e africanas.

Uma partilha do sensível fixa, portanto, ao mesmo tempo, um comum partilhado e partes exclusivas. Essa repartição das partes e dos lugares se funda numa partilha de espaços, tempos e tipos de atividade que determina propriamente a maneira como um comum se presta à participação e como uns e outros tomam parte nessa partilha. ${ }^{18}$

Ainda são muito recentes as propostas de desconstrução desta ordem. Em Belém, a presença indígena no patrimônio cultural da cidade traduz bem como o sensível é partilhado a partir das relações de poder.

\section{No Frontal da Basílica de Nazaré}

Em Belém, todos os anos, no mês de outubro, acontece a maior procissão católica do mundo, o Círio de Nossa Senhora de Nazaré, que costuma levar mais de dois milhões de pessoas para as ruas da cidade. O percurso por onde passa a berlinda da santa atravessa os dois centros históricos da cidade e é nesta região que está localizado o patrimônio cultural arquitetônico tombado pelo IPHAN. O final da procissão acontece na Basílica de Nossa Senhora de Nazaré, que compõe o CAN, Conjunto Arquitetônico Nazareno (Figura 2). Sem dúvida nenhuma, esta igreja é um dos pontos turísticos mais importantes da cidade e um espaço significativo da religião católica e das marcas da colonização.

${ }^{18}$ RANCIÈRE, Jacques. A Partilha do Sensível. São Paulo: Editora 34, 2005, p.15. 
Figura 02 - Centro Arquitetônico Nazareno.

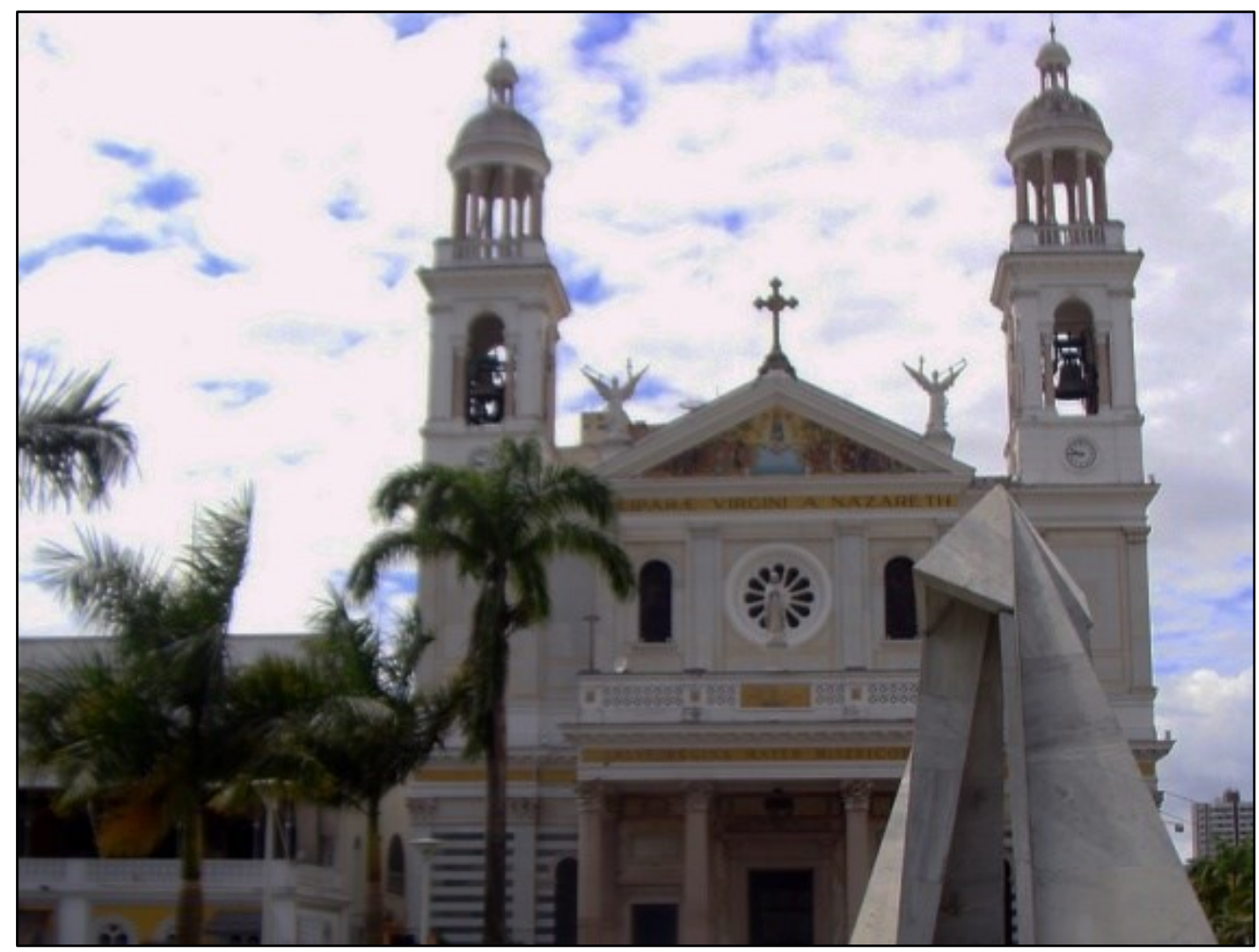

Foto: Acervo Pessoal da Autora, 2017.

As figuras 03 e 04, a seguir, mostram o frontal da Basílica, localizado logo abaixo da cruz. Nele está pintada uma tela com a fundação de Belém. Trata-se de uma imagem comprometida em apresentar o momento em que começou o processo de "civilização" da população local. O enunciado visual retoma o discurso da catequização indígena como evolução.

Figura 03 - Frontal da Basílica de Nazaré.

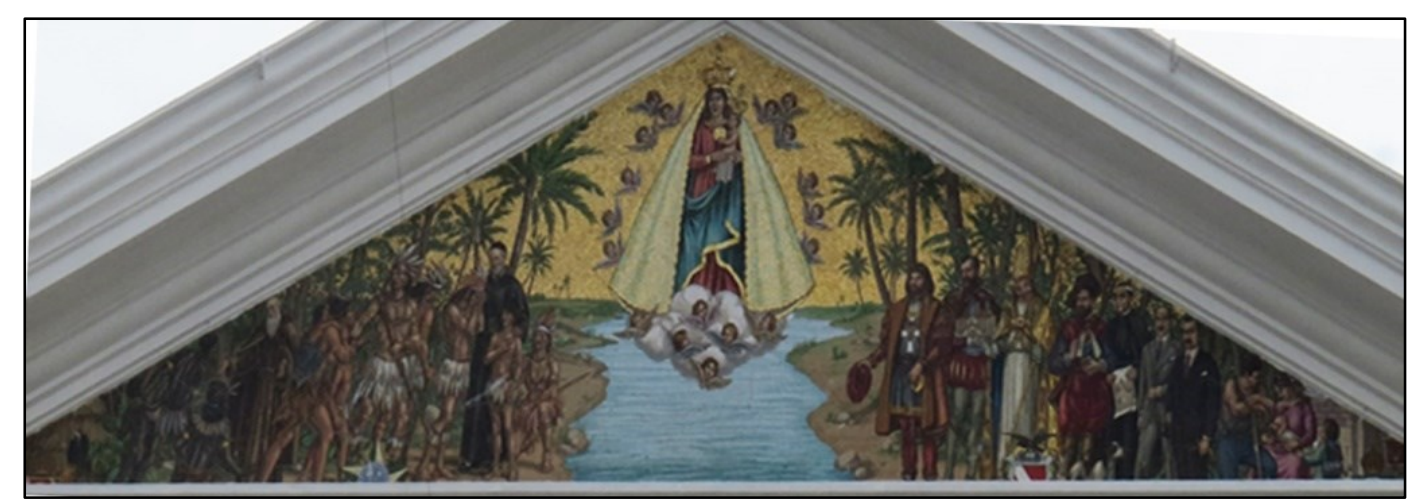

Foto: Acervo Pessoal da Autora, 2017. 
Figura 04 - Detalhe do Frontal da Basílica de Nazaré.

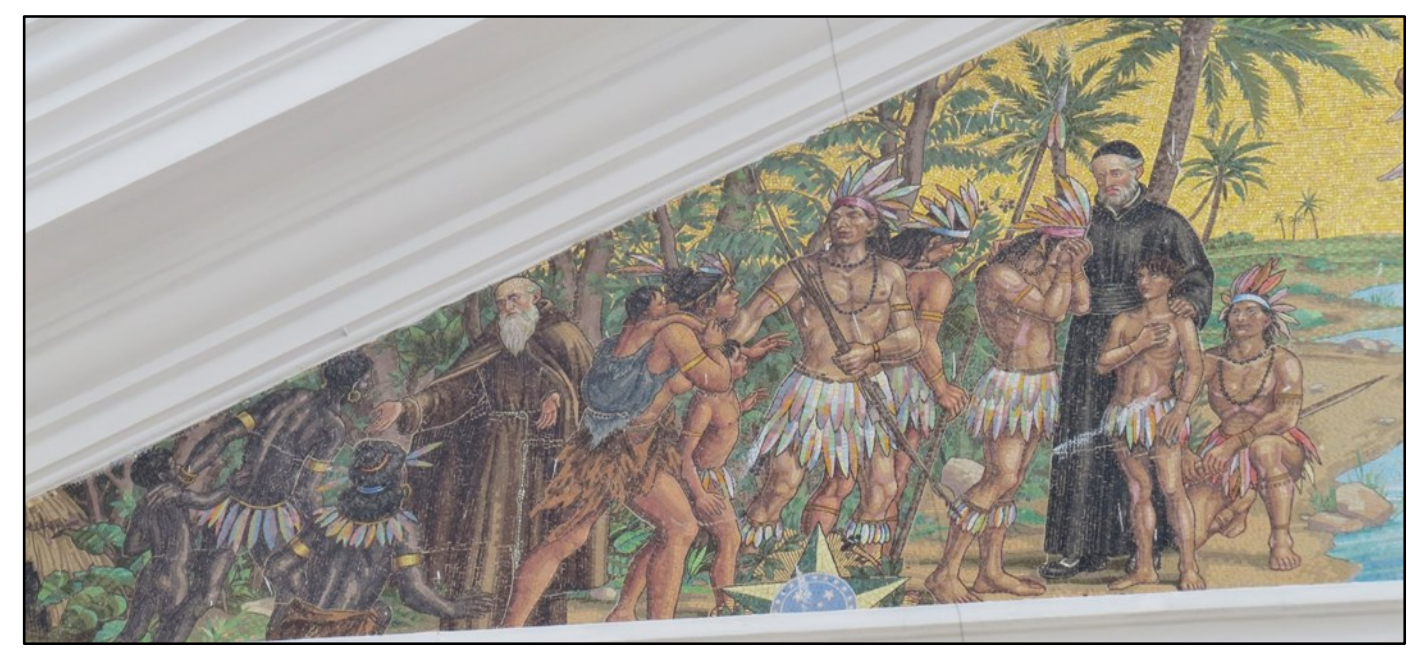

Foto: Acervo Pessoal da Autora, 2017.

No lado direito estão os portugueses, no centro a presença da santa flutuando sobre um rio e os indígenas à esquerda, acompanhados pelos de religiosos católicos, uma alusão direta ao processo de "pacificação" dos indígenas. Neste espaço oficializado como patrimônio, há a presença dos indígenas, mas eles aparecem como sujeitos tutelados pela igreja, de forma bastante subalternizada, como evidencia a próxima imagem. Não é difícil perceber a hierarquização destes sujeitos.

A Igreja Católica participou diretamente do processo de colonização do continente americano. No início do século XVI, a Companhia de Jesus foi criada exclusivamente para auxiliar na conquista ibérica das terras ultramarinas. Na primeira fase do sistema colonial, quando Espanha e Portugal agenciavam o comércio das especiarias, sem dúvida o Vaticano representou uma espécie de metrópole das metrópoles, pois as determinações papais estabeleciam os critérios de governamentalidade das populações indígenas e africanas, inclusive determinando quem era pessoa e que era animal irracional. Esta imagem, tão cordial dos religiosos, não traduz o que foi o poder católico nas fronteiras da Amazônia brasileira, mas se ergue como patrimônio oficial da cidade de Belém.

\section{Na Praça Brasil, um indígena solitário}

No centro da praça, aparece a escultura de um índio de bronze (Figura 5). Esta escultura foi encomendada na Europa e trazida para Belém pelo comerciante dono dos Armazéns Guarany. "A estátua em bronze representando um índio guarani foi fundida pelo 
artista plástico francês J. Maclesset em 1900. Pertencia a particular que doou-a a prefeitura de Belém para ser instalada na praça, o que ocorreu em 1933". ${ }^{19}$

Figura 05 - Praça Brasil.

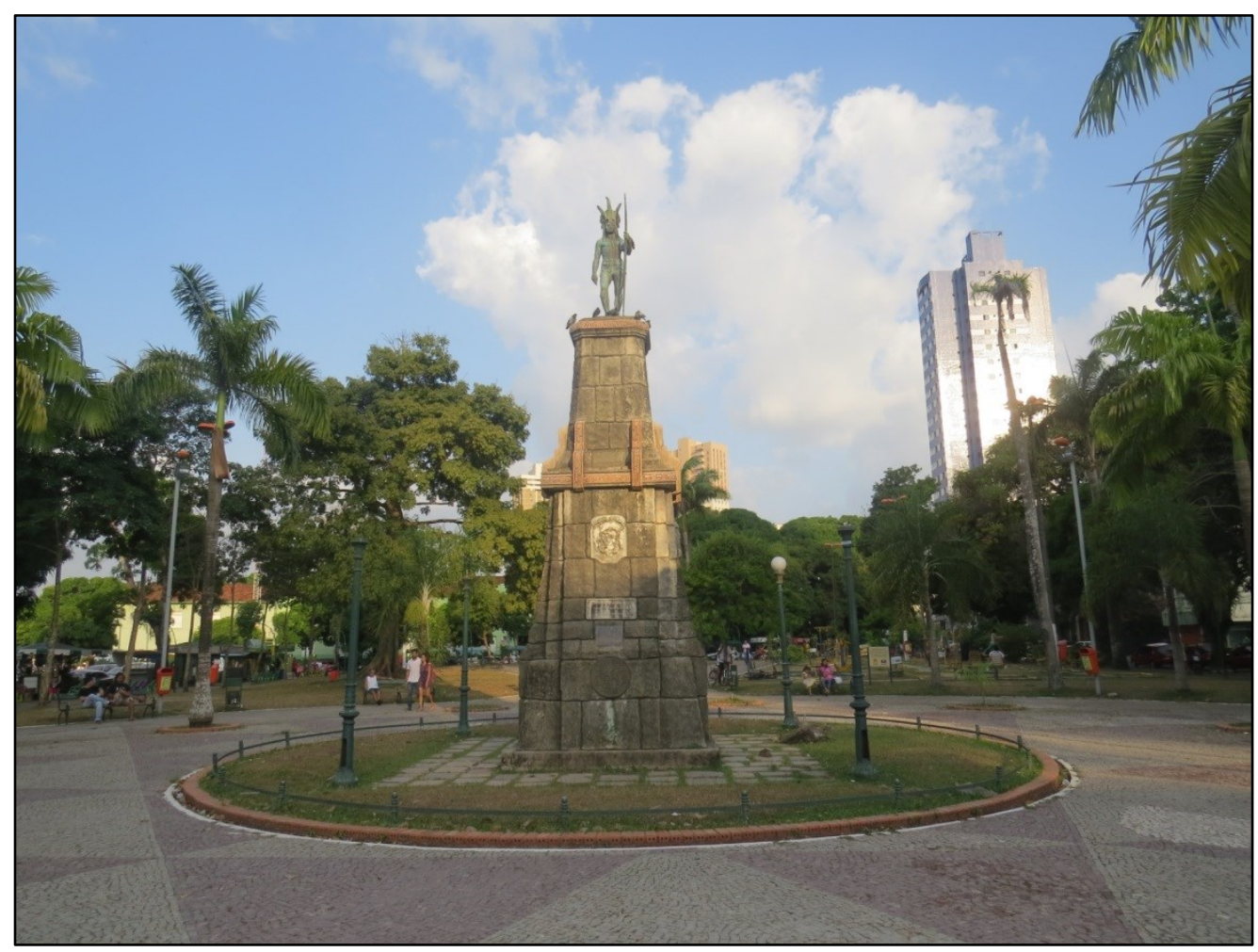

Foto: Acervo Pessoal da Autora, 2017.

Depois que a loja fechou, a escultura foi doada para a prefeitura e colocada no centro dessa praça, que passou a se chamar Praça do Índio, embora existam outras versões para este acontecimento. Quando foi criada, este era um lugar muito pobre de Belém, um espaço favelizado, mas com o crescimento da cidade, hoje esta praça se localiza num bairro nobre, muito valorizado. Em frente à Praça Brasil há o suntuoso prédio do Tribunal Regional do Trabalho e vários edifícios muito luxuosos. Com este novo contexto de urbanização, ela não podia mais continuar com esta denominação e passou a ser a Praça Brasil para os moradores da cidade, embora oficialmente seja Praça Santos Dumont. Trata-se de um espaço de lazer muito dinâmico, mas curiosamente, a maioria das pessoas que vai à Praça Brasil nunca viu esse índio, embora ele não seja pequeno.

19 SOARES, Elizabeth Nelo (org.). Largos, coretos e praças de Belém - PA. Brasília: IPHAN; Programa Monumenta, 2009, p. 166. 


\section{Nos muros da periferia palavras e imagens de Cely Feliz}

Para finalizar as análises, agora vou sair do patrimônio oficial e colocar os olhos nos muros e paredes de Belém às vésperas das comemorações dos quatrocentos anos da cidade, período em que explodiu a presença indígena e negra nos grafites. Este movimento administrado por coletivos, grafiteiras e grafiteiros reivindicou uma memória plural pra cidade.

Figura 06 - "Vai vestir roupa piquenuzinho!"

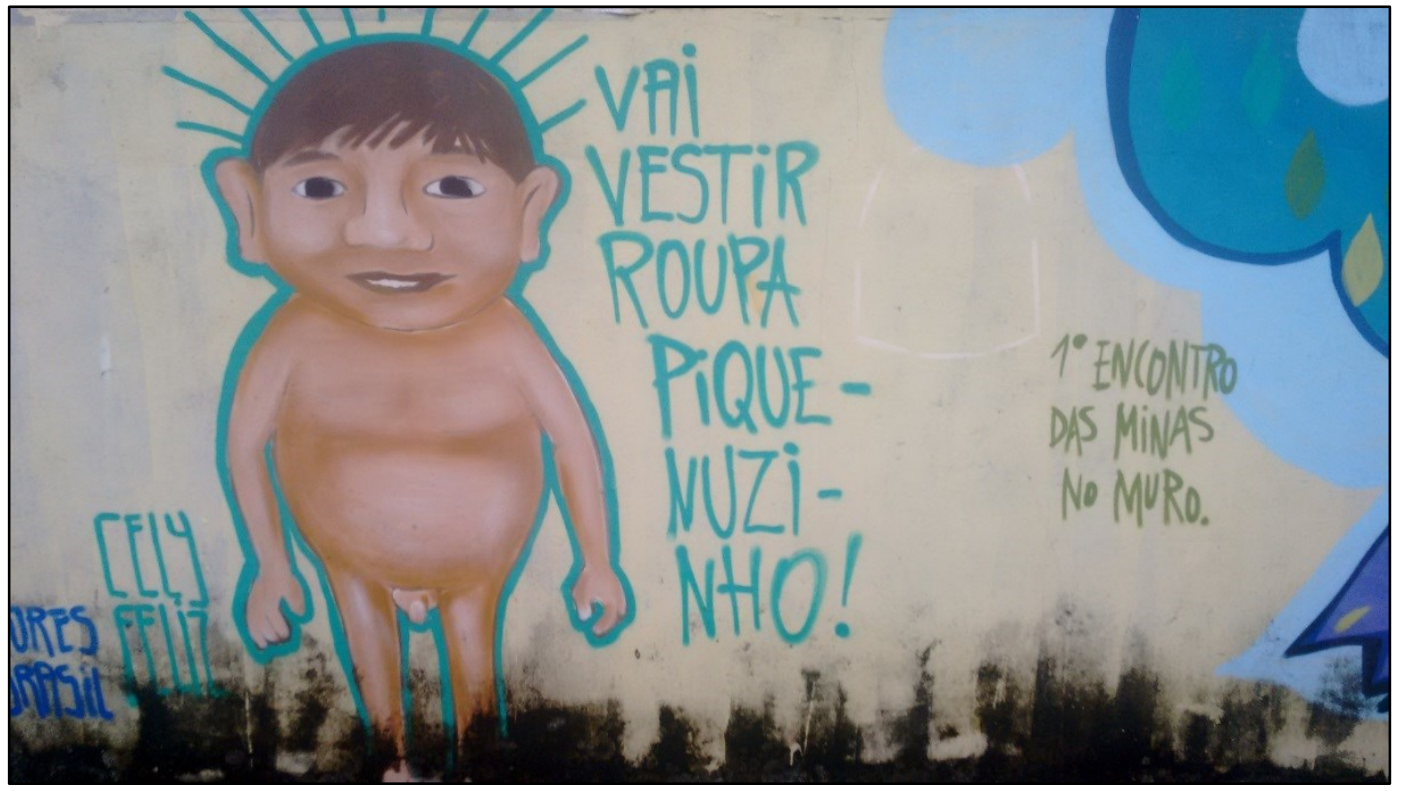

Foto: NASCIMENTO, Camille. A presença indígena nos grafites de Belém: entre fraturas e resistências. 2017. Dissertação (Mestrado em Comunicação) - Universidade Federal do Pará, Belém, p. 53.

Este grafite é também de Cely Feliz, a artista da imagem polêmica da mulher indígena na rede. Ela insiste em representar corpos indígenas nos muros de Belém e nesta imagem também um enunciado verbal com marcação étnica. "Vai vestir roupa, piquenuzinho!", no ritmo do português falado em Belém ganha uma entoação muito particular, herdada do Nheengatu, a Língua Geral Amazônica, pertencente ao tronco linguístico tupi, a língua mais falada na região de Belém até a primeira metade do século XIX. Nos muros, a fala macia do belenense cadenciada pelas línguas indígenas e a imagem de um garoto indígena apresentam outra cidade, ou melhor, pluralizam a Belém europeia das comemorações oficiais dos 400 anos.

Compreender a complexidade de uma etniCidade implica em considerar a diversidade de línguas e os processos históricos de seus apagamentos. A língua portuguesa só vai virar a língua majoritária na Amazônia, depois de suprimida a grande revolta popular que ficou conhecida como Cabanagem, em 1840. Até este momento, apenas um pequeno grupo de pessoas falava português na região. O apagamento das línguas indígenas reforçou a marginalização dos saberes locais e produziu nas populações locais o mito da língua única, 
numa região em que vivem tantos povos indígenas. O grafite de Cely Feliz incentiva essa remexida na história das línguas da cidade de Belém.

\section{Nas ilhas de Belém do Pará com Sebá Tapajós}

A área metropolitana de Belém é formada por uma grande península e 39 ilhas. Durante as comemorações dos 400 anos, a programação oficial da prefeitura ignorou quase toda a população dessas ilhas e apenas em Mosqueiro e Outeiro havia alguma comemoração. Em reação a esta exclusão, o grafiteiro Sebá Tapajós teve a iniciativa de criar um projeto chamado Street River. Junto com outros grafiteiros famosos internacionalmente, ele foi para ilha do Combu e realizou o grande projeto de grafitar nas casas dos moradores. Os artistas pintaram não só imagens de indígenas famosos, mas estamparam também os próprios moradores nas casas, cujo fenótipos traduzem evidentes descendência indígena e africana.

\footnotetext{
Sebá Tapajós idealizou uma galeria fluvial, na qual as casas e os barcos dos moradores da Ilha do Combu substituíram as telas, levando para esta localidade tanto os grafites já produzidos nos projetos e exposições anteriores, como também grafites novos, feitos exclusivamente para este evento, com imagens dos próprios moradores. ${ }^{20}$
}

$\mathrm{Na}$ imagem ao fundo (Figura 7) está grafitada a dona desta casa. Os moradores das ilhas ganharam visibilidade justamente para fazer uma crítica às comemorações oficial dos 400 anos. Na imagem seguinte (Figura 8), para marcar mais acentuadamente a presença indígena, o cacique Raoni, uma das principais lideranças do movimento indígena foi grafitado.

${ }^{20}$ NASCIMENTO, Camille. A presença indígena nos... Op., p. 110. 
Figura 07 - Mulher amazônica na ilha do Combu.

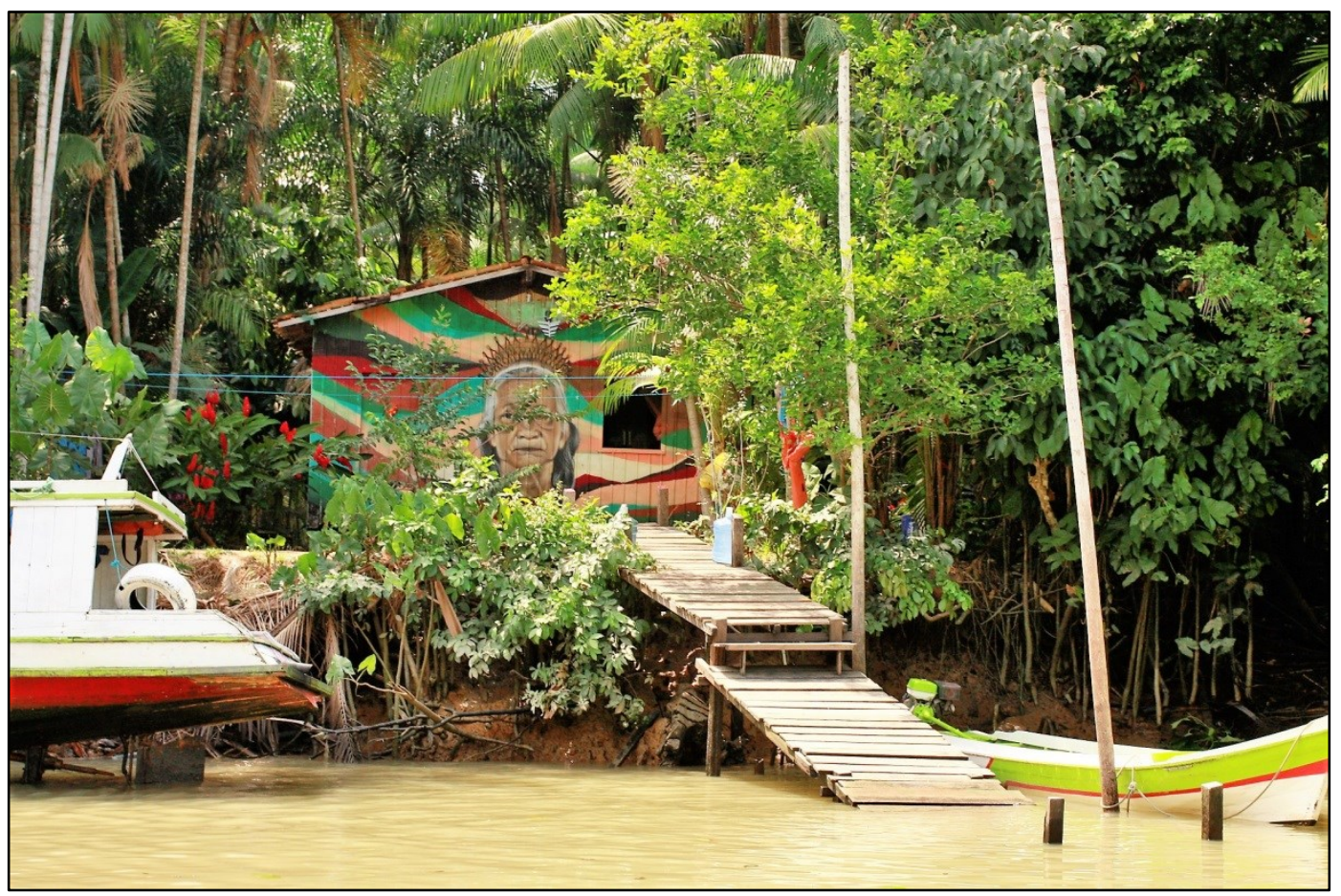

Foto: NASCIMENTO, Camille. A presença indígena nos grafites de Belém: entre fraturas e resistências. 2017. Dissertação (Mestrado em Comunicação) - Universidade Federal do Pará, Belém, p. 107.

Figura 08 - Cacique Raoni.

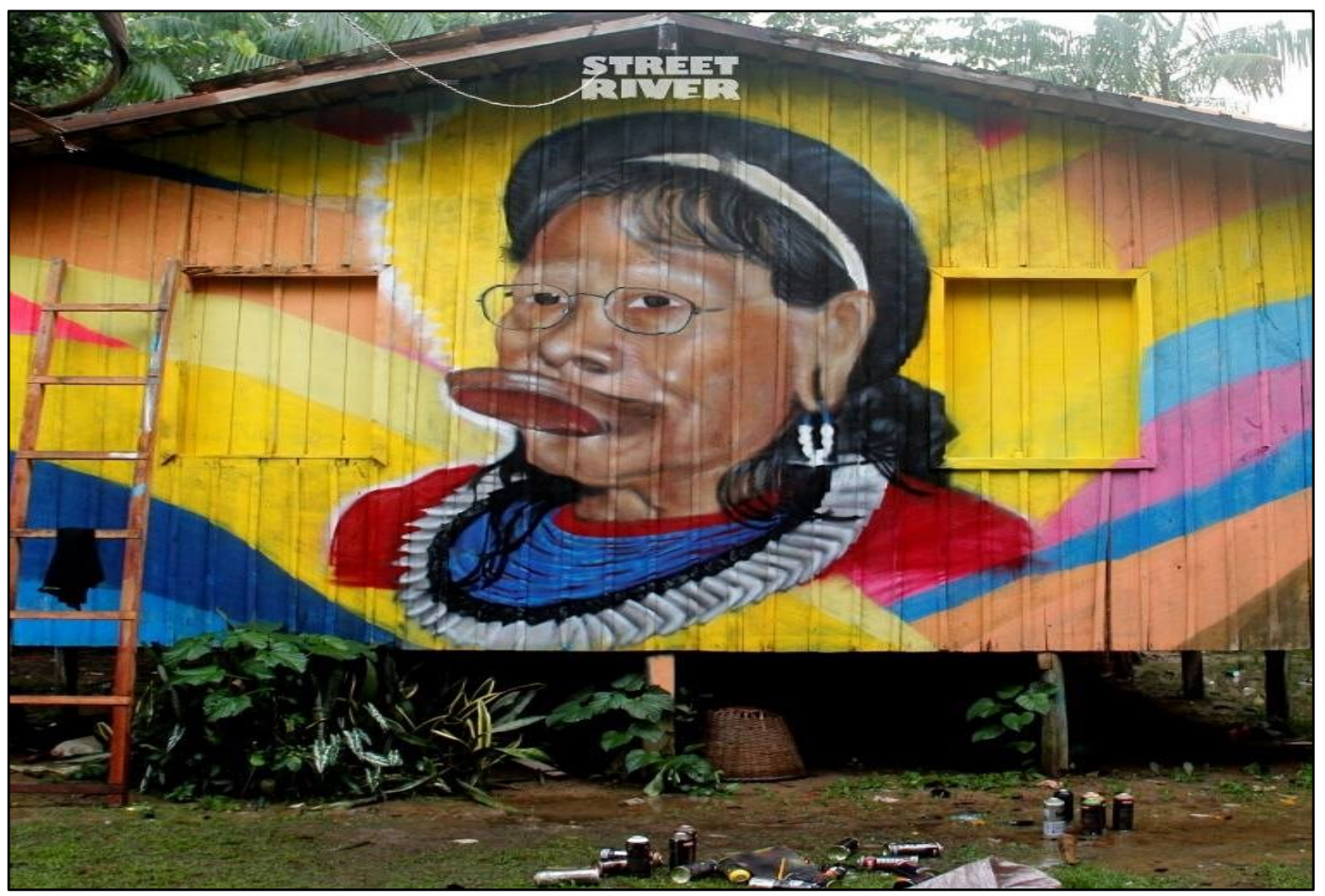

Fonte: [Reprodução]. [s./d.]. Disponível em: http://sebatapajos.com.br/. Acesso em: 03 maio 2015. 
O projeto reivindicou a inclusão das sujeitas e sujeitos que vivem nas regiões das ilhas, nas comemorações dos 400 anos. Diante destes acontecimentos, não há como negar que se por um lado o patrimônio cultural de Belém exclui, ou trata o indígena de uma forma menor, por outro, a cidade interativa escreve outras versões da história, move-se em várias direções e nos apresenta aquilo que eu chamo hoje de etiniCnidade.

A pluralidade de sentidos dos grafites ao mesmo tempo em que traduz as transformações históricas, também ajuda a promovê-las e reafirma a posição de que os acontecimentos podem ter seus regimes de dizer modificados a partir das emergências da história. Em Belém, este processo se evidenciou bastante, neste período dos 400 anos, nos muros e as grafiteiras e os grafiteiros produziram novas experiências de enunciar a cidade, que desafiou a memória oficial.

\section{Considerações Finais}

Nas análises aqui propostas, aparecem diferentes perspectivas do patrimônio cultural da cidade de Belém. O dispositivo colonial continua exibindo seus poderosos tentáculos e quase não encontramos a presença indígena no patrimônio cultural salvaguardado pelas instituições estatais, mas isso não conseguiu impedir a própria cidade de reagir e ampliar os sentidos da etniCidade.

Nas dinâmicas da globalização da atualidade, como alerta Yúdice, a diversidade cultural não pode mais se limitar a seus conteúdos, mas sim, precisa ser entendida como um recurso, isto é, a partir de finalidades diversas, sobretudo em expedientes que envolvem desenvolvimento econômico, promoção da cidadania e lutas por justiça social.

Hoje em dia é quase impossível encontrar declarações públicas que não arregimentem a instrumentalização da arte e da cultura, ora para melhorar as condições sociais, como na criação de tolerância multicultural e participação cívicas, através de defesas como as da UNESCO pela cidadania cultural e por direitos culturais, ora para estimular o crescimento econômico através de projetos de desenvolvimento cultural e urbano e a concomitante proliferação de museus para o turismo cultural. ${ }^{21}$

A noção da cultura como recurso a ser gerido desestabilizou as noções de alta cultura e cultura popular, ela considera criticamente o consumo, mas politiza os diversos hibridismos e trânsitos das práticas culturais de hoje, abarca as formas ambíguas de geração de desenvolvimento econômico, inclusão social e cidadania. Agora, a cultura passa num circuito de processos comunicacionais em que produtos e obras são compreendidos dentro de performances encenadas e as "mesmas" práticas culturais ocupam posições diferentes. A mídia e a cultura podem ser uma experiência em fluxos transnacionais, que ampliam questões como

${ }^{21}$ YÚDICE, George. A Conveniência da Cultura: usos da cultura na era global. Belo Horizonte: Ed. UFMG, 2004, p. 27. 
imperialismo, a relação centro e periferia e demanda novas compreensões sobre representações sociais e processos de mediação.

A compreensão e a prática da cultura são bastante complexos, situados na intercessão das agendas da economia e da justiça social. A cultura é cada vez mais invocada não somente como uma propulsora do desenvolvimento do capital; repetiu-se ad nauseum que a indústria audiovisual só perde para a indústria aeroespacial nos estados Unidos. ${ }^{22}$

Incentivadas pelos usos das novas tecnologias, as transformações por que passaram as formas de interação, somadas às novas configurações do poder, que em muitos países deixou de ser centralizado em um Estado nacionalista, interferiram numa pluralização ainda mais acentuada da diversidade cultural. O momento atual evidencia, com mais vigor, a flexibilização das identidades e as possibilidades de negociação em relação à cultura local, agora, necessariamente entendida a partir da produção de diversos saberes, muitas vezes até paradoxais, entre si.

Diante do caráter performativo dos diferentes lugares ocupados pela cultura é necessária também uma nova proposta epistemológica, que consiga assinalar as relações de poder que constituem estes lugares. Nesta direção, as noções de etniCidade e dispositivo colonial podem ser bem produtivas, pois ajudam a remexer os estereótipos e os lugares de enunciação autorizados.

Para ampliar as diferentes percepções dos lugares de fala sobre as produções de sentido acerca desta movimentação cultural que envolve não só Belém, mas as diferentes cidades amazônicas, de forma geral, e seus descontínuos trajetos históricos são válidas as formulações de Kellner sobre uma metodologia de análise multiperspectívica. ${ }^{23}$ A visão multiperspectívica consiste em uma forma de estratégia que possibilita compreender, por meio de diferentes ângulos, como se materializam as interpretações de uma perspectiva cultural e histórica em várias direções de ações, pesquisas e análises, permitindo a construção de um mosaico de interpretações.

Fazer funcionar o ponto de vista multiperspectívico, em relação à diversidade cultural, consiste em ampliar as acepções das identidades amazônicas. A respeito deste estereótipo, afirma Maués:

Nada disto deve nos fazer esquecer a pobreza e o sofrimento da grande maioria da população regional, nem as ameaças existentes numa forma incontrolada e predatória de exploração das riquezas dessa mesma região. Mas também não nos permite olhá-la por um só ângulo, ou ficar nos seus exotismos, sem buscar o aprofundamento necessário para pesquisar e buscar encontrar a compreensão a respeito de como as populações amazônicas realmente constroem sua vida e sua cultura. ${ }^{24}$

22 YÚDICE, George. A Conveniência da Cultura... Op. cit., p. 35.

23 KELLNER, Douglas. A cultura da mídia. Bauru, SP: Ed. EDUSC, 2001.

24 MAUÉS, R. H. Outra Amazônia... Op. cit., p. 16. 
Diante de tantas nuances que envolvem a história dessa região, é imperativo questionar, como indica Foucault, as "sínteses acabadas", na maioria das vezes, aceitas antes de qualquer exame, esses laços cuja validade é reconhecida desde o início. É preciso desalojar essas naturalizações. E ao invés de deixá-las ter valor espontaneamente, apreendê-las no jogo das relações de poder, a partir de seus tantos silêncios constitutivos. ${ }^{25}$

${ }^{25}$ FOUCAULT, Michel. Sobre a História... Op. cit., p. 24. 


\section{Referências}

DAMASCENO, José. Entre o rio e a ponte: letras e identidades às margens do Rio Acará, na Amazônia paraense. 2012. Dissertação (Mestrado em Comunicação, Linguagem e Cultura) Universidade da Amazônia, Belém.

DE CERTEAU, Michel. A invenção do cotidiano. Vol. 1: Artes de fazer. Petrópolis, RJ: Vozes, 1998.

FERRARA, Lucrécia. As mediações da paisagem. Revista Líbero, São Paulo, v. 15, n. 29, p. 4350, 2012.

FOUCAULT, Michel. Em defesa da sociedade: curso no College de France (1975-1976). São Paulo: Martins Fontes, 2005.

FOUCAULT, Michel. Sobre a História da Sexualidade. In: Microfísica do poder. Rio de Janeiro: Graal, 2007.

KELLNER, Douglas. A cultura da mídia. Bauru, SP: Ed. EDUSC, 2001.

MARTÍN-BARBERO, J. A Comunicação na Educação. São Paulo: Contexto, 2014.

MAUÉS, R. H. Outra Amazônia: os santos e o catolicismo popular. Norte Ciência, v. 2, n. 1, p. 1-26, 2011.

MIGNOLO, Walter. Histórias Locais / Projetos Globais: Colonialidade, Saberes Subalternos e Pensamento Liminar. Belo Horizonte: Ed. UFMG, 2003.

NASCIMENTO, Camille. A presença indígena nos grafites de Belém: entre fraturas e resistências. 2017. Dissertação (Mestrado em Comunicação) - Universidade Federal do Pará, Belém.

NEVES, Ivânia. A Invenção do índio e as narrativas orais tupí. 2009. Tese (Doutorado em Comunicação) - Universidade de Campinas, Campinas (SP).

NEVES, Ivânia. EtniCidades: os 400 anos de Belém e a presença indígena. Revista Moara, n. 43, jan.-jul. 2015.

PEREIRA, Nilza. Uma visão espacial e sociodemográfica da população indígena no Brasil, com base no Censo Demográfico 2010. In: INSTITUTO Brasileira de Geografia e Estatística. Atlas Nacional Digital do Brasil 2016. (Recurso Eletrônico). Disponível em: https://www.ibge.gov.br/apps/atlas_nacional/. Acessado em: 15 dez. 2019.

PIZARRO, Ana. As Vozes do Rio. Belo Horizonte: Ed. UFMG, 2012.

RAMA, Angel. A cidade das letras. São Paulo: Brasiliense, 1985.

RANCIÈRE, Jacques. A Partilha do Sensível. São Paulo: Editora 34, 2005.

SOARES, Elizabeth Nelo (org.). Largos, coretos e praças de Belém - PA. Brasília: IPHAN; Programa Monumenta, 2009.

VELHO, Gilberto. Patrimônio, negociação e conflito. Mana, Rio de Janeiro, PPGAS/MN/UFRJ, v. 12, n. 1, p. 237-248, 2006.

YÚDICE, George. A Conveniência da Cultura: usos da cultura na era global. Belo Horizonte: Ed. UFMG, 2004. 